\title{
A Qualitative Exploration Of Action Learning: Undergraduate Students' Attitudes
}

Alvin Rosenstein, (E-mail: rosenste@adelphi.edu), Adelphi University Rakesh Gupta, (E-mail: gupta@adelphi.edu), Adelphi University Allan Ashley, (E-mail: ashley@adelphi.edu), Adelphi University

\begin{abstract}
This continuing research seeks to build upon our understanding of undergraduate student attitudes regarding Action Learning and specifically to qualitatively probe their perceptions of its positive and negative aspects.
\end{abstract}

\section{INTRODUCTION}

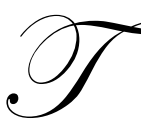

chis is the third in a series of articles and conference presentations that interested faculty at the Adelphi University School of Business have undertaken in exploring the utility of Action Learning for teaching both undergraduate and graduate business courses.

To briefly review its philosophical basis, Action Learning is grounded in the pragmatic functional philosophy of John Dewey, arguably the most significant and influential educator of the twentieth century. He critiqued traditional, classroom-based education and maintained that experience, learning and development are interconnected. $\mathrm{He}$ argued that students achieve the greatest and most durable mastery of a discipline only when they are provided the opportunity to put into real world practice the principles they learn from text and in the classroom.

"....out of the occupation, out of doing things that are to produce results there is born a discipline of its own kind and type. Our whole conception of school discipline changes when we get this point of view. In critical moments we realize that the only discipline that stands by us, the only training that becomes intuition is that got through life itself. That we learn from experience, and from books or the sayings of others only as they are related to experience, are not mere phrases.”(Dewey, 1915, pp. 13-15)

Believing this, he stressed that the school must provide opportunity for the interplay of thinking and doing in a manner that replicates the challenges that the student will face in the real world. He practiced what he preached and in so doing embraced and popularized the practice of student teaching, a hallmark of contemporary teacher education.

"..there are only one or two (university chairs of pedagogy) that have tried to make a connection between theory and practice. (Other schools) teach for the most part by theory, by lectures, by reference to books, rather than through the actual work of teaching itself." (Dewey, 1915, p. 82)

Others, including the authors, have applied his Action Learning philosophy to their own disciplines.

\section{BACKGROUND AND PURPOSE OF THE PRESENT RESEARCH}

The first presentation of our Action Learning research reviewed the history and principles of Action Learning and set forth its basic tenets as interpreted and implemented in Marketing courses at Adelphi University (Rosenstein et al, 2004). 
The second in the series reviewed empirical data that demonstrated that both undergraduate and graduate students preferred the Action Learning mode (of teaching Marketing), to the more traditional lecture and discussion mode of instruction. However, the superiority of Action Learning was more pronounced for the graduate students than for the undergraduate students. The conclusion from the data was that the undergraduates, while also preferring the Action Learning mode, missed the familiar structure of the more traditional pedagogy, more so than did the graduate students (Gupta et al, 2005).

The present research seeks to increase our understanding of undergraduate student attitudes; specifically, to qualitatively probe their perceptions of its positive and negative aspects. Such a qualitative approach in assessing the teaching mode, as perceived by the participants, is consistent with the work of Chris Argyris. In essence, we are using Argyris' mode of "Action Research" in order to assess action learning (Woodell, 2003).

\section{THE COURSE AND THE DATA COLLECTION PROCEDURES}

The course that provided the basis for this study was an advanced undergraduate course in Marketing Strategy, which was taught in the Action Learning mode consistent with the principles described elsewhere (Rosenstein et al, 2004).

In brief, the students working in teams developed strategic plans for actual clients (who largely consisted of businesses with which they had some connection).

During the course of the semester, they progressed through modules which sequentially dealt with Situation/Opportunity Analysis, SWOT Analysis and Development of Marketing Objectives, Target Market Analysis (which included fielding surveys of the target market), Product/Service Positioning and then the development of an appropriate Marketing Mix.

With each module, the professor provided perspectives, guidance and examples on how to proceed. Following this, each student applied the lessons learned in completing his or her module assignment. Next the professor provided feedback, which the student incorporated in his/her paper. The best paper was then selected as the team template for that module.

At the end of the semester, the students were given anonymous self-administered questionnaires, which provided the basis for the qualitative analysis.

\section{FINDINGS}

The findings developed in this research are consistent with those summarized in the previous paper (Gupta et al 2005), in that the undergraduate business students again demonstrated a preference for the Action Learning mode of instruction over the traditional lecture and discussion method.

The students were asked: "How do you feel about Action Learning as a teaching technique for this course, as opposed to a more traditional lecture and discussion approach?" They then were provided the following alternatives (in order of presentation):

- "Strongly prefer traditional lecture and discussion"

- " "Prefer traditional lecture and discussion"

- "No preference for either technique"

- "Prefer action learning approach"

- "Strongly prefer action learning"

Action learning emerged as the preferred mode of teaching. The results are summarized below $(\mathrm{N}=23$ students who responded to question). 


\author{
Strongly Prefer \\ Traditional
}

3

\author{
Prefer \\ Traditional
}

3

\section{No \\ Preference}

5
Prefer Action

Action Learning

4
Strongly Prefer

Action Learning

\section{8}

The difference between the percent of students who preferred Action Learning (52\%) and those who preferred Traditional Learning (26\%), while consistent with previous research, is not significant. This lack of significance may be attributed to the small sample size.

It was not only a question of preference; the students also obviously liked the Action Learning mode of teaching -- in and of itself.

They were asked, "If you had to do it over again, would you take this course?" and were provided the following alternatives. "Definitely," "Probably," Undecided," Probably Not," and "Definitely Not."

All indicated they either definitely "Definitely" (83\%) or "Probably" (17\%) would take the course.

\section{QUALITATIVE ANALYSIS OF ATTITUDES REGARDING ACTION LEARNING}

When asked for the reasons for their preference for Action Learning over the traditional teaching mode, the students primarily focused on the value they found in the "hands-on" approach, which they felt was superior to the traditional mode in facilitating initial learning and/or recall.

The tables below summarize their reactions in explaining their preference for Action Learning.

\section{Reasons For Preference Of Action Learning Over Traditional Learning}

Learn/retain more

More interesting/stimulating

Prepares for future/real life

Learned/benefited from group work
$($ Base $=12)$

\begin{tabular}{ll}
$\#$ & $\%$ \\
\hline 6 & $50 *$
\end{tabular}

325

$2 \quad 17$

$2 \quad 17$

* Percentage totals greater than $100 \%$ because of multiple mentions

Representative verbatim responses are presented below:

- $\quad$ "I like action learning better because I feel I can walk away with something. In other courses I take a test and usually forget the information. I don't think I will forget what I learned in this course."

- $\quad$ "I feel that test-taking is only short-term memory and by actually participating in the world you learn a lot more and retain the information."

- $\quad$ "This helps the student learn more. I feel you get bored in lectures. Action Learning is a way to make the student feel more involved."

- "Action learning is more mind-stimulating. It is more of a hands-on approach to learning, getting out there in the real world as opposed to sitting and being lectured for over two hours a week."

- $\quad$ "It is much easier to comprehend teaching by action learning." 
The students not only felt they learned more from the Action Learning mode, but they also indicated they actually found the Action Learning classes enjoyable. When the students were probed for why they indicated that if they "had to do it over again," they still would take the course, about half used words such as "liked/enjoyed," "interesting" and "fun" to describe their reactions.

\section{Words Used To Explain Attitudes Towards Action Learning Course}

\begin{tabular}{llr} 
& \multicolumn{2}{l}{ (Base = 24) } \\
\cline { 2 - 3 } & & $\%$ \\
Students who used at least one of these words (net) & 11 & 47 \\
Students who said "liked/enjoyed" & 8 & 33 \\
Students who said "interesting" & 5 & 21 \\
Students who said "fun" & 2 & 8
\end{tabular}

Representative verbatim responses are presented below:

- $\quad$ "I learned a lot from Professor Rosenstein because of Action Learning. Hands-on learning is the best way for me to grasp concepts. The atmosphere in the class was fun and enjoyable. The class was always interesting and helpful to my marketing specialization."

- "I think it was interesting because the class is more about learning from your experience than taking notes in class. I enjoyed becoming part of the project by doing surveys."

- $\quad$ "I liked hands-on learning. This sort of learning seems very practical and more useful than learning out of a text book."

When specifically asked about the knowledge they derived from the course, the students primarily focused on specific usable skills they acquired.

Most Important Knowledge Derived From Marketing Strategy Course Taught In The Action Learning Mode

\# students responding (net)

Learning to develop marketing/business plan/strategy

Learning to conduct research/surveys

Learning to identify/understand target markets

Mention of specific skills

Tabulation \& analysis

SWOT analysis

Interviewing techniques

\begin{tabular}{lr}
\multicolumn{2}{c}{$($ Base $=22)$} \\
$\#$ & $\%$ \\
\hline 19 & 86 \\
& \\
8 & 33 \\
5 & 23 \\
2 & 9 \\
& \\
2 & 9 \\
1 & 5 \\
1 & 5
\end{tabular}

Illustrative verbatim responses follow:

- "I learned how to do research for a marketing plan and how to put together a marketing plan."

- "I learned the steps of a marketing plan (opportunity analysis, etc.) and how to implement a marketing plan."

- $\quad$ "I learned identifying target markets and creating marketing strategy." 
When asked how the course might be improved, $41 \%$ of the students said no improvements were necessary and $23 \%$ did not respond to the question (possibly because they felt no improvements were necessary). However, $36 \%$ suggested a diversity of changes. While no two students suggested the same improvement, the common theme that ran through most of the suggestions was a need for greater structure in the course. This was reflected in the following diverse suggestions: "more direction," "stronger syllabus," "more visuals," "more tasks for project," and "stick to traditional approach."

The desire for greater structure voiced by roughly one-quarter of the students is consistent with the hypothesis developed regarding previous Action Learning research (Gupta et al, 2005 ).

The authors currently are collecting more undergraduate and graduate student feedback across several courses in an attempt to continue to increase their understanding of student response to the Action Learning teaching modality and to fine-tune these courses in a manner consistent with effective pedagogy and student priorities.

\section{REFERENCES}

1. Dewey, John (1915). The School and Society. Chicago: University of Chicago Press.

2. Gupta, R., Ashley, A. and Rosenstein, A. (2005) Implementing Action Learning in Marketing Research Courses. Proceedings of Northeast Decision Sciences Institute, March 2005 [CD-ROM].

3. Koo, L.C. (1999). Learning Action Learning. Journal of Workplace Learning. Vol. 11, No. 3, pp. 89-94.

4. Leitch, C. and Harrison, R. (1999). A process model for entrepreneurship education and development. International Journal of Entrepreneurial Behaviour \& Research. Vol. 5, No.3, pp. 83-101.

5. Raelin, J.A. and Schermerhorn Jr., J. (1994) A new paradigm for advanced management education-how knowledge merges with experience, editorial, Management Learning, Vol. 25, No. 2, pp. 195-200.

6. Rosenstein, A., Gupta, R. and Ashley, A. (2004) Action Learning - A 'New' Teaching Tool for Undergraduate Business Education. Journal of College Teaching and Learning, Vol. 1, No. 5, pp. 99-103.

7. Woodell, Victor (2003). An Interview with Chris Argyris. Organization Development Journal, Vol. 21, No. 2, pp. 67-70. 


\section{NOTES}

